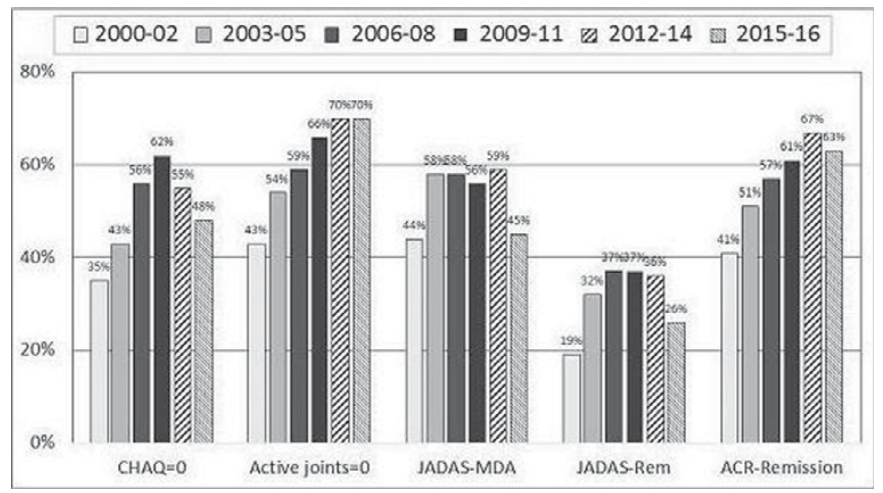

Conclusions: In recent years, children have been treated earlier, received less concomitant treatment with NSAIDS, corticosteroids as well as DMARDs. More recent cohort of patients had less severe disease at baseline, but also showed a markedly better outcome already at one year of treatment reflected by higher rates of patients with no active joint, a CHAQ DI of 0, a JADAS-MDA, and ACR-Remission. These data suggest that early disease control and better pre-selection of patients who need biologics are important to improve outcome and safety in children with JIA.

Disclosure of Interest: G. Horneff Speakers bureau: Abbvie, Pfizer, Roche, Novartis, MSD, K. Minden Speakers bureau: Abbvie, Pfizer, Roche, Genzyme, Pharm-Allergan, I. Foeldvari: None declared, G. Ganser: None declared, J. Haas: None declared, J. Brunner: None declared, I. Becker: None declared DOI: 10.1136/annrheumdis-2017-eular.1866

\section{OP0197 EVALUATION OF A DOSING REGIMEN FOR TOCILIZUMAB IN PATIENTS YOUNGER THAN TWO YEARS OF AGE WITH SYSTEMIC JUVENILE IDIOPATHIC ARTHRITIS}

N.L. Mallalieu ${ }^{1}$, J. $\mathrm{Hsu}^{1}$, K. Wang ${ }^{1}$, S. Wimalasundera ${ }^{2}$, C. Wells ${ }^{2}$, I. Calvo Penades $^{3}$, R. Cuttica ${ }^{4}$, H.I. Huppertz ${ }^{5}$, R. Joos ${ }^{6}$, Y. Kimura ${ }^{7}$, D. Milojevic ${ }^{8}$, M. Rosenkranz ${ }^{9}$, K. Schikler ${ }^{10}$, T. Constantin ${ }^{11}$, C. Wouters ${ }^{12} .{ }^{1}$ Roche Innovation Ctr, New York, United States; ${ }^{2}$ Roche Products Ltd, Welwyn Garden City, United Kingdom; ${ }^{3}$ Hosp Universitario y Politécnico la Fe, Valencia, Spain; ${ }^{4}$ Hosp General de Niños Pedro de Elizalde, Buenos Aires, Argentina; ${ }^{5}$ Professor Hess Children's Hosp, Bremen, Germany; ${ }^{6}$ ZNA Jan Palfijn Antwerpen, Antwerp, Belgium; ${ }^{7}$ Hackensack U Med Ctr, Hackensack; ${ }^{8}$ Tufts Med Ctr, Boston; ${ }^{9}$ Children's Hosp Pittsburgh UPMC, Pittsburgh; ${ }^{10} \mathrm{U}$ Louisville Hosp, Louisville, United States; ${ }^{11}$ Semmelweis U, Budapest, Hungary; ${ }^{12} \cup$ Hosp Gasthuisberg, Leuven, Belgium

Background: Tocilizumab (TCZ) is approved for the treatment of systemic juvenile idiopathic arthritis (sJIA) based on clinical trials in patients (pts) $\geq 2$ years of age. This study (NP25737) is the first for a biologic in SJIA pts $<2$ years of age. Objectives: To evaluate the pharmacokinetics (PK), pharmacodynamics (PD), efficacy, and safety of TCZ in SJIA pts $<2$ years of age in a phase 1 trial.

Methods: Pts with uncontrolled SJIA and symptoms for $\geq 1$ month prescreening who failed treatment with corticosteroids and NSAIDs and had no history of allergy to TCZ or other biologics received open-label TCZ $12 \mathrm{mg} / \mathrm{kg}$ intravenously (IV) every 2 weeks (dose calculated at each visit based on body weight). Pts were treated up to week 12 and could continue until the age of 2 years or were treated for 1 year from baseline. End points included PK (primary) at week 12, PD and efficacy (exploratory), and safety. Comparison was made to exposures from a previous trial in SJIA pts $\geq 2$ years of age (WA18221) that was the basis for approval of TCZ in SJIA.

Results: Eleven pts were enrolled; median (range) age was 16 (10-22) months and weight was $10.40(6.8-11.5) \mathrm{kg}$. Serum TCZ concentrations, estimated using population PK analysis, peaked immediately after infusion; median (range) maximum concentration was $282(195-347) \mu \mathrm{g} / \mathrm{mL}$ (steady state reached by week 12), and median (range) trough concentration was $34.3(19.2-59.7) \mu \mathrm{g} / \mathrm{mL}$. Peak and trough exposures were within the exposure range in older children (244 [109-382] to 54.3 [10.9-117] $\mu \mathrm{g} / \mathrm{mL}$; Figure). Observed mean \pm SD soluble IL-6 receptor levels were $47.65 \pm 16.40 \mathrm{ng} / \mathrm{mL}$ at baseline and $927.83 \pm 148.07 \mathrm{ng} / \mathrm{mL}$ at day 71 . CRP levels were $250.81 \pm 425.11 \mathrm{mg} / \mathrm{L}$ and $2.80 \pm 3.56 \mathrm{mg} / \mathrm{L}$, respectively. ESR levels were $59.40 \pm 27.47 \mathrm{~mm} / \mathrm{h}$ and $2.00 \pm 1.00 \mathrm{~mm} / \mathrm{h}$, respectively. Mean $\pm S D$ Juvenile Arthritis Disease Activity Score-71 improved from $22.27 \pm 10.09$ at baseline to $3.66 \pm 4.66$ at day 71 . By week 12,10 pts had 32 adverse events (AEs) and 4 withdrew due to AEs. Infections or infestations were the most frequently reported AEs (10 events, 9 pts). Five serious AEs (SAEs) occurred; 3 pts had SAEs of hypersensitivity that led to withdrawal; 1 of these pts then experienced SAEs of foot and mouth disease and SJIA flare after study withdrawal. No actual cases of MAS were reported, but 2 pts had laboratory abnormalities indicative of MAS according to 2016 criteria. ${ }^{1}$ No deaths occurred during the study.

Conclusions: TCZ exposures achieved in this study fell within the range of the previous trial in SJIA pts $\geq 2$ years of age. This study provides evidence that TCZ is effective in SJIA pts $<2$ years of age, achieves PK and efficacy similar to those

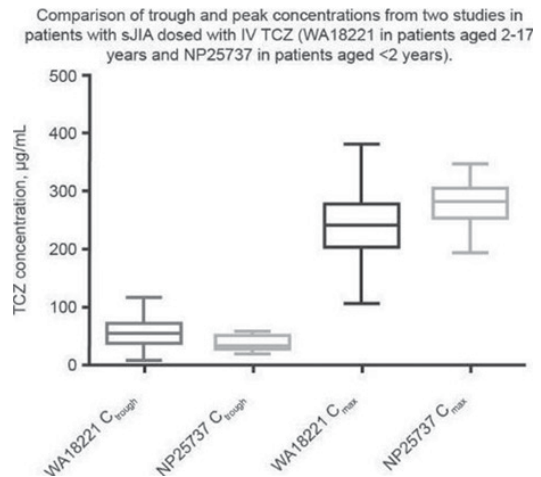

demonstrated previously in older pts, and has a similar AE safety profile, but there was a higher incidence of serious hypersensitivity events and suspected MAS. References:

[1] Ravelli A et al. Ann Rheum Dis. 2016;75:481-9.

Disclosure of Interest: N. Mallalieu Shareholder of: Roche, Employee of: Roche, J. Hsu Employee of: Roche, K. Wang Employee of: Roche, S. Wimalasundera Employee of: Roche Products Ltd., C. Wells Employee of: Roche Products Ltd., I. Calvo Penades: None declared, R. Cuttica Consultant for: Roche, Novartis, Lilly, GlaxoSmithKline, Bristol-Myers Squibb, Janssen, Speakers bureau: Roche, Novartis, Lilly, GlaxoSmithKline, Bristol-Myers Squibb, Janssen, H. Huppertz: None declared, R. Joos: None declared, Y. Kimura Consultant for: Novartis, SOBI, D. Milojevic: None declared, M. Rosenkranz: None declared, K. Schikler: None declared, T. Constantin: None declared, C. Wouters: None declared DOI: 10.1136/annrheumdis-2017-eular.2386

\section{THURSDAY, 15 JUNE 2017 Barrier free employment for young people with RMDs}

\section{OP0198-PARE FIT FOR WORK ONLINE: SUPPORTING EMPLOYEES WITH RMDS, EMPLOYERS AND HEALTHCARE PROFESSIONALS}

G. OLeary. Arthritis Ireland, Dublin 2, Ireland

Background: Seven million working days are lost each year in Ireland due to RMDs, such as back \& neck pain or stiffness, arthritis, and limb pain. This is therefore a significant problem which obviously impacts on both employers, employees and healthcare professionals. That is why Arthritis Ireland has developed Fit for Work Online - an eLearning programme which focuses on the issues that face these three groups.

Objectives: The objective of the project was to develop an online educational programme to provide information, guidance and support to employees, employers and healthcare professionals on working with RMDs.

Methods: In 2015 Arthritis Ireland began its developments of an online education programme "Fit for Work Online" which focuses on the tripartite relationship between the employee, employer and healthcare professional.

3 video lessons were developed as part of this eLearning programme.

- The first lesson is aimed at employees who are living with an RMD

- The second lesson is aimed at employers who have a staff member who is living with an RMD (and finally)

- The third has been developed for health professionals to update them on current guidance around RMDs and ongoing employment

A key message in all 3 videos is that working is good for your health.

Since employment has been shown to boost health and happiness, it is crucial, whenever possible, that people who are living with an RMD, remain in employment, or return to work, as soon as they can. That is the central message of this eLearning programme.

A number of issues were addressed in the development of this programme in order to convey these important issues:

- Firstly, employees who are living with an RMD are encouraged to take control of their condition. People living with an RMD are encouraged to consider practical steps and issues which would support them in staying in, or returning to, work.

- Secondly, from an employer's perspective, in addition to concerns about the welfare of their employees, there are other issues to consider, and it is natural for instance to be concerned about the possible impact of any health condition on their employees' performance \& reliability, and consequently on their business. Adaptations, supports, flexibility and so on need to be considered.

- Finally, health professionals need to encourage, advise and facilitate people who are living with RMDs to remain in, or return to work.

Results: The Fit for Work Online programme will go live in February 2015. It is planned that a report on the first four months of the programme's delivery and implementation will be available at EULAR 2017 in Madrid.

Conclusions: The direct cost of RMDs at work in Ireland is estimated to be 


\section{Arthritis Ireland
Little Things make a Big Difference}

at least $€ 750$ million a year. Ensuring that people who have been recently diagnosed with an RMD (or who have been living with one for a long time), have the opportunity to remain in or return to work, is central to the ideas behind Fit-for-Work. Everyone has a role to play to make this happen, and everyone needs to be flexible \& realistic, because in the end of the day, everyone stands to benefit.

Disclosure of Interest: None declared

DOI: 10.1136/annrheumdis-2017-eular.6281

\section{OP0199-PARE SUPPORT TO STAY EMPLOYED AND SOCIAL SECURITY ARRANGEMENTS FOR WORK DISABILITY DUE TO RA - PERCEPTIONS OF PATIENTS WITH RA AND RHEUMATOLOGISTS IN 31 EUROPEAN COUNTRIES}

P. Putrik ${ }^{1}$, S. Ramiro ${ }^{2}$, F. Guillemin ${ }^{3}$, B. Rojkovich ${ }^{4}$, F. Sivera ${ }^{5}$, M. de Wit ${ }^{6}$ A. Woolf ${ }^{7}$, A. Zink ${ }^{8}$, T. Sokka ${ }^{9}$, A. Boonen ${ }^{1}$ on behalf of Working Group Access to Social Security for patients with RA across Europe. ${ }^{1}$ Rheumatology, MUMC, Maastricht; ${ }^{2}$ Rheumatology, Leiden University Medical Center, Leiden,

Netherlands; ${ }^{3}$ University of Lorraine, Nancy, France; ${ }^{4}$ Polyclicic of the Hospitaller Brothers of St. John of God, Budapest, Hungary; ${ }^{5}$ Hospital General Universitario de Elda, Alicante, Spain: ${ }^{6}$ VU University Medical Centre, Nijmegen, Netherlands; ${ }^{7}$ Royal Cornwall Hospital, Truro, United Kingdom; ${ }^{8}$ DRFZ, Berlin, Germany;

${ }^{9}$ Jyväskylä Central Hospital, Jyväskylä, Finland

Background: Despite demonstrated influence of country of residence on labour force participation among patients with RA, little attempt has been made to understand the users' perceptions of support and social security (SS) systems. Objectives: To explore the patterns in perceptions among patients with RA and rheumatologists from different European countries across five domains (1) importance and support to remain employed, (2) process of applying for WD, (3) obtaining and living with WD pension, (4) role of the rheumatologists in support to remain employed or apply for WD pension and (5) performance of the system. Methods: A survey among RA patients and rheumatologists was conducted in 44 countries of European WHO Region. For each domain, several questions (4 to 6 questions per domain, each on a 1-5 Likert answer scale, dichotomized as 1 ("totally (agree)") and 0 ("not agree, not disagree", "totally (disagree)") were asked (Table). Next, sum scores were calculated for each domain and averaged per country. The domain "remaining employed" was assessed in patients who currently have or ever had work. Analyses in domains "process of applying for WD" and "obtaining and living with WD" were limited to patients who currently have or ever considered applying for WD. Comparisons of scores in all domains were explored by: EU-15, new EU member states and non-EU countries, the five types of social welfare system (Anglo-Saxon, Bismarckian, Mediterranean, Post-Communist, and Scandinavian) and by countries' wealth (GDP per capita adjusted for purchasing power parity [PPP]) using ANOVA or Pearson correlation, as appropriate.

\begin{tabular}{|c|c|c|c|c|c|c|}
\hline \multicolumn{7}{|c|}{$\begin{array}{l}\text { Table. Differences in perceptions of the social security system among patients and } \\
\text { rheumatologists by GDP, system type and EU membership status. }\end{array}$} \\
\hline & & \multicolumn{3}{|c|}{ Perceptions among patients } & \multicolumn{2}{|c|}{$\begin{array}{c}\text { Perceptions among } \\
\text { rheumatologistş् }\end{array}$} \\
\hline & & $\begin{array}{c}\text { Importance } \\
\text { and support } \\
\text { to remain } \\
\text { employed } \\
(0-4)\end{array}$ & $\begin{array}{l}\text { Process of } \\
\text { applying for } \\
\text { WD } \\
(0-6)\end{array}$ & $\begin{array}{l}\text { Obtaining and } \\
\text { living with } \\
\text { WD } \\
(0-4)\end{array}$ & $\begin{array}{c}\text { Performanc } \\
\text { e of SS } \\
\text { system } \\
(0-4)\end{array}$ & $\begin{array}{c}\text { Role of } \\
\text { rheumatologis } \\
(0-4)\end{array}$ \\
\hline & & \multicolumn{5}{|c|}{ Mean $(S D)$} \\
\hline \multirow{2}{*}{ GDP } & $\begin{array}{l}\text { GDP }<27,000 \\
\text { USD PPP per } \\
\text { capita }(n=16)\end{array}$ & $1.68(0.48) \xi$ & $2.10(0.98) \varepsilon$ & $1.22(0.61) E$ & $1.39(0.51) \varepsilon$ & $2.38(0.53) \alpha$ \\
\hline & $\begin{array}{l}\text { GDP } \geq 27,000 \\
\text { USD PPP per } \\
\text { capita }(n=15)\end{array}$ & $1.85(0.60) \xi$ & $2.67(1.03) E$ & $1.27(0.57) f$ & 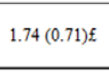 & $1.91(0.51) \alpha$ \\
\hline \multirow{5}{*}{$\begin{array}{l}\text { Type of } \\
\text { system }\end{array}$} & $\begin{array}{c}\text { Anglo-Saxon } \\
(\mathrm{n}=1)\end{array}$ & $0.75(.)^{\star}$ & $0.92(.)^{*}$ & $0.67(.)^{\star}$ & $0.83(.)^{*}$ & $2.00()$. \\
\hline & $\begin{array}{c}\text { Bismarckian } \\
(\mathrm{n}=5 \\
\text { (patients); } \mathrm{n}=6 \\
\text { (rheumatologi } \\
\text { sts)) }\end{array}$ & $1.77(0.29)$ & $2.35(0.34)$ & $1.26(0.70)$ & $1.91(0.36)$ & $1.71(0.23)$ \\
\hline & $\begin{array}{c}\text { Mediterranean } \\
(\mathrm{n}=7)\end{array}$ & $1.88(0.54)$ & $2.12(0.79)$ & $1.17(0.51)$ & $1.35(0.87)$ & $2.12(0.74)$ \\
\hline & $\begin{array}{c}\text { Post- } \\
\text { Communist } \\
(\mathrm{n}=15)\end{array}$ & $1.71(0.52)$ & $2.24(0.94)$ & $1.22(0.63)$ & $1.44(0.52)$ & $2.32(0.53)$ \\
\hline & $\begin{array}{c}\text { Scandinavian } \\
(\mathrm{n}=3)\end{array}$ & $2.86(0.48)^{*}$ & $4.18(1.14)^{*}$ & $1.66(0.35)^{*}$ & $2.36(0.07)^{*}$ & $2.11(0.55)$ \\
\hline \multirow{3}{*}{$\underset{\text { status }}{\mathrm{EU}}$} & $\begin{array}{l}\mathrm{EU}-15 \\
(\mathrm{~N}=12)\end{array}$ & $1.97(0.66)$ & $1.18(0.59)$ & $2.24(0.88)$ & $1.59(0.73)$ & $1.84(0.50)^{\star}$ \\
\hline & $\begin{array}{c}\text { EU new } \\
\text { member states } \\
(\mathrm{n}=11)\end{array}$ & $1.83(0.53)$ & $1.24(0.62)$ & $2.25(1.05)$ & $1.59(0.60)$ & $2.22(0.43)$ \\
\hline & $\begin{array}{c}\text { Non-EU } \\
(n=8)\end{array}$ & $1.66(0.65)$ & $1.34(0.58)$ & $2.76(1.23)$ & $1.54(0.64)$ & $2.42(0.64)^{*}$ \\
\hline
\end{tabular}

Results: Of 44 countries, $31(70 \%)$ and $30(68 \%)$ have provided data for patients and rheumatologists, respectively. In total, 646 patients (mean age (SD) 53 (12), $76 \%$ female, 519 (78\%) ever worked) and 500 rheumatologists filled in the questionnaires. Overall, positive weak to no relationships were present between the GDP per capita and perceptions from rheumatologists or patients about SS arrangements. However, significant differences were observed across the systems type with the Scandinavian type (Finland, Norway, Sweden) consistently scoring higher than the others on most domains (table). Remarkably, rheumatologists in less wealthy and non-EU countries felt more confident in their role related to WD pension.

Conclusions: Patients'a nd rheumatologists' perceptions of systems to support persons with RA encountering work restrictions varied mostly according to the type of the social welfare system, while remarkably little differences were related to country's wealth and membership in EU. Scandinavian employment support and social security system appeared to most adequately meet the expectations of patients and rheumatologists in questions of remaining at work and application to WD pension.

Disclosure of Interest: None declared

DOI: 10.1136/annrheumdis-2017-eular.4319

\section{THURSDAY, 15 JUNE 2017 \\ Epidemiology of rheumatic and musculoskeletal diseases - a critical appraisal}

\section{OP0200 CONFOUNDING BY INDICATION WILL MAKE NON-TNFI BDMARDS APPEAR MORE HARMFUL THAN TNFI BDMARDS - A NATIONWIDE STUDY OF CHANNELING IN SWEDEN} 2010-2014

T. Frisell ${ }^{1}$, E. Baecklund ${ }^{2}$, K. Bengtsson ${ }^{3}$, D. Di Giuseppe ${ }^{1}$, H. Forsblad-d'Elia ${ }^{4}$ J. Askling ${ }^{1}$ on behalf of the ARTIS Study Group. ${ }^{1}$ Karolinska Institutet, Stockholm; ${ }^{2}$ Uppsala University, Uppsala: ${ }^{3}$ Sahlgrenska Academy, Göteborg; ${ }^{4}$ Umeå University, Umeå, Sweden

Background: Confounding by indication occurs when factors associated with the choice of therapy are also predictors of the studied outcome, and is generally considered the major limitation of non-randomized comparisons of different therapies. In RA, age, sociodemographic factors, disease activity, and medical history may influence the choice of e.g. a non-TNFi over a TNFi bDMARD. The degree of bias is difficult to assess since most studies have limited data on potential confounders, and residual confounding cannot be separated from true treatment effects.

Objectives: To quantify the expected confounding by indication caused by baseline differences in patient characteristics at initiation of different bDMARDs in RA.

Methods: All RA patients in the Swedish Rheumatology Register (SRQ) were linked to nationwide registers to assess whether a comprehensive list of covariates predicted the choice of bDMARD to such a degree that different rates of adverse events (AEs) would be expected. Among considered confounders were demographic variables, RA related factors (including RF, disease duration, $\mathrm{HAQ}$, DAS28 w. components) and medical history (health care utilization and 20 specific conditions).

We used historical data on the 5 year risk of several AEs among RA patients starting any bDMARD 2005-2009 to predict the risk among RA patients (bionaïve and switching from a first TNFi) starting specific bDMARDs 2010-2014. Risk was modelled in logistic regressions, as a function of baseline characteristics but assuming no effect from the therapy itself.

Results: Patients starting non-TNFi were older than those starting a TNFi, had lower socioeconomic status, higher disease activity and more often a history of diseases including malignancy, serious infections, and diabetes. These factors were in general also significant predictors of $\mathrm{AEs}$, and the predicted proportions of all AEs were substantially higher for non-TNFi compared to TNFi bDMARDs, highest for rituximab. Within the TNFi-group, only minor differences were seen. Age was a strong confounder, and standardizing to the age/sex-distribution of the TNFi group reduced the group difference dramatically.

Predicted percentage with AE within 5 years, based on observed baseline characteristics. Crude and standardized to age-sex distribution of TNFi as first bDMARD

\begin{tabular}{|c|c|c|c|c|c|c|c|c|c|c|}
\hline & \multicolumn{2}{|c|}{$\begin{array}{l}\text { All-cause } \\
\text { mortality }\end{array}$} & \multicolumn{2}{|c|}{$\begin{array}{c}\text { All-cause } \\
\text { hospitalization }\end{array}$} & \multicolumn{2}{|c|}{ Malignancy } & \multicolumn{2}{|c|}{ MACE } & \multicolumn{2}{|c|}{$\begin{array}{l}\text { Serious } \\
\text { infection }\end{array}$} \\
\hline & Crude & Std & Crude & Std & Crude & $\overline{\text { Std }}$ & Crude & Std & Crude & Std \\
\hline \multicolumn{11}{|c|}{ First bDMARD } \\
\hline TNFi & 4.9 & & 60.3 & & 5.4 & & 6.2 & & 15.3 & \\
\hline Rit. & 12.8 & 6.7 & 74.0 & 67.6 & 7.7 & 5.7 & 11.9 & 7.3 & 25.6 & 18.9 \\
\hline Toc. & 8.5 & 7.7 & 63.6 & 64.2 & 5.8 & 5.2 & 8.4 & 8.8 & 19.4 & 18.8 \\
\hline Aba. & 11.6 & 6.9 & 67.5 & 61.5 & 6.2 & 5.0 & 12.4 & 7.1 & 22.1 & 17.3 \\
\hline \multicolumn{11}{|c|}{ Switch from TNFi } \\
\hline TNFi & 5.3 & 5.5 & 68.8 & 68.6 & 5.0 & 5.1 & 7.0 & 7.2 & 17.8 & 18.0 \\
\hline Rit. & 7.8 & 6.4 & 74.6 & 71.7 & 5.7 & 4.9 & 9.3 & 7.3 & 22.4 & 20.1 \\
\hline Toc. & 6.5 & 6.8 & 72.3 & 68.3 & 5.3 & 5.0 & 8.4 & 8.0 & 19.8 & 18.8 \\
\hline Aba. & 7.5 & 5.6 & 71.1 & 71.4 & 5.5 & 5.0 & 8.8 & 7.6 & 20.7 & 18.9 \\
\hline
\end{tabular}

Conclusions: Even if there are no true differences in risk by bDMARD, 